University of Nebraska - Lincoln

DigitalCommons@University of Nebraska - Lincoln

Congreso internacional sobre iconografía

precolombina, Barcelona 2019. Actas.

$7-20-2020$

\title{
Iconografía en el paisaje. Vida cotidiana y prácticas sociales en el arte rupestre en el noreste de México
}

Luis J. Abejez

Cristina Corona Jamaica

Follow this and additional works at: https://digitalcommons.unl.edu/actas2019

Part of the American Material Culture Commons, Indigenous Studies Commons, Museum Studies Commons, Other History of Art, Architecture, and Archaeology Commons, and the Other Languages, Societies, and Cultures Commons

This Article is brought to you for free and open access by the Zea E-Books at DigitalCommons@University of Nebraska - Lincoln. It has been accepted for inclusion in Congreso internacional sobre iconografía precolombina, Barcelona 2019. Actas. by an authorized administrator of DigitalCommons@University of Nebraska - Lincoln. 


\title{
Iconografía en el paisaje. Vida cotidiana y prácticas sociales en el arte rupestre en el noreste de México
}

\author{
Luis J. Abejez ${ }^{1}$ y Cristina Corona Jamaica ${ }^{2}$
}

1 Laboratorio de Patrimonio y Turismo Cultural (LABPATC). Universitat de Barcelona / Red IBERTUR. abejez@gmail.com 2 Doctoranda, Universitat Pompeu Fabra, Barcelona; INAH, México. cristinacoronaj@gmail.com

\begin{abstract}
Resumen
El noreste de México es una de las áreas más ricas en arte rupestre del país. Durante miles de años, los grupos humanos que habitaron esta región dejaron constancia de su presencia por medio de las pinturas y grabados que realizaron en cuevas, abrigos y rocas. El estudio interdisciplinar de este lenguaje visual puede proporcionar una valiosa información para el conocimiento de esas poblaciones. Entre otros aspectos, permite una aproximación a su pensamiento simbólico, la percepción que tenían del mundo físico y espiritual, y cómo percibieron y utilizaron el territorio en su cotidianidad.
\end{abstract}

Palabras clave: Arte rupestre, Noreste de México, Iconografía, Identidad, Paisaje

\begin{abstract}
Northeastern Mexico is one of the richest rock art areas in the country. For thousands of years, the human groups that inhabited this region left a record of their presence through the paintings and engravings they made in caves, shelters and rocks. The interdisciplinary study of this visual language can provide valuable information for the knowledge of these populations. Among other topics, it allows an approach to their symbolic thought, their perception of the physical and spiritual world, and how they perceived and used the territory in their daily lives.
\end{abstract}

Keywords: Rock art, Northeastern Mexico, Iconography, Identity, Landscape

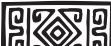

Landscape is the work of the mind. Its scenery is built up as much from strata of memory as from layers of rock.

- Simon Schama, Landscape and Memory

\section{Introducción}

Desde los primeros momentos de la conquista de México, las grandes culturas mesoamericanas llamaron la atención de los cronistas españoles, que dejaron multitud de escritos que describían aquellas sociedades. La monumentalidad de su arquitectura y el interés político motivaron, igualmente, que desde el siglo XIX la arqueología en México centrara en ellas sus estudios. Por el contrario, los pueblos cazadores y recolectores del Norte, sin grandes construcciones y con un modo de vida sencillo en apariencia, apenas despertaron la curiosidad de los cronistas ni, hasta hace escasas décadas, de la arqueología, lo que ha provocado un cierto desconocimiento de estos grupos. Las escasas descripciones históricas, a menudo sesgadas por los intereses de los colonizadores y evangelizadores, hacen que la arqueología y el estudio del arte rupestre sean imprescindibles para el conocimiento de estas sociedades.

En el Noreste, además, estos estudios son de particular relevancia al ser una de las zonas más ricas en arte rupestre de todo el país. El gran número de sitios,

Publicado en Congreso internacional sobre iconografía precolombina, Barcelona 2019. Actas, Victòria Solanilla Demestre, editora (Lincoln, Nebraska: Zea Books, 2020). https://doi.org/10.32873/unl.dc.zea.1242 


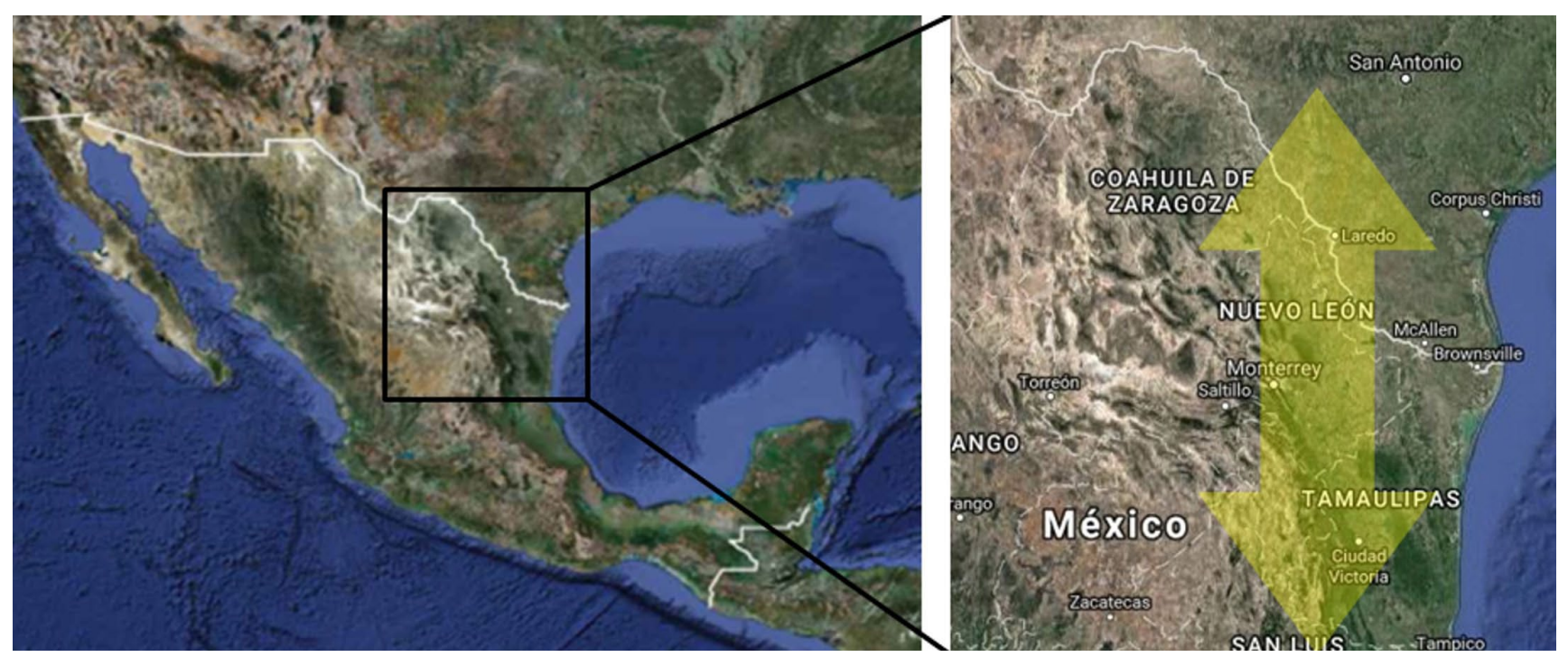

Figura 1. La región noreste de México (modificado de Google Maps).

su variedad y distribución, que con algunas diferencias se extiende por toda la región, evidencia su importancia en el pasado. El estudio de las pinturas y grabados realizados en cuevas, abrigos, rocas y objetos portátiles, de los estilos, técnicas, motivos y características, de su ubicación, asociaciones y relaciones con el entorno natural, etc., facilita una singular aproximación a la cultura material e inmaterial de los pueblos del Noreste y de las diversas circunstancias que ayudaron a conformar sus culturas e identidades.

A través del arte rupestre, estos grupos expresaron la compleja interacción que durante miles de años mantuvieron con su entorno, visualizando en la piedra la estrecha relación que establecieron entre lo temporal y lo espacial, lo material y lo simbólico, lo cotidiano y lo espiritual. Esta complejidad sistémica hace necesario un estudio interdisciplinar que integre los datos arqueológicos, históricos, etnográficos, etc. conjuntamente con la comprensión diacrónica del territorio, de su geografía, flora, fauna, etc., con objeto de contextualizar física, mental, espacial y temporalmente este tipo de manifestaciones.

Asimismo, su larga permanencia en el tiempo, desde época prehistórica hasta bien entrado el siglo XIX, convierte al arte rupestre en un testimonio fundamental para el estudio de los diferentes procesos (históricos, sociales, ideológicos, etc.) que se dieron en el Noreste. Es decir, permite observar los cambios, permanencias y transformaciones en las sociedades que vivieron en este territorio con una perspectiva de larga duración que facilita una mejor comprensión de estos procesos.

\section{El espacio geográfico y humano}

La región del noreste de México comprende los estados de Coahuila, Nuevo León, Tamaulipas y el área desértica de San Luis Potosí, formando el llamado "Corredor del noreste mexicano" (Murray, 2012). El territorio se caracteriza por un clima extremo y árido, así como por la omnipresencia de la Sierra Madre Oriental, que extiende su abrupta orografía de norte a sur, lo que ha definido no solamente el medioambiente y una ecología particular sino también las dinámicas vitales de los grupos humanos a lo largo de la historia.

Para comprender estas dinámicas, en el Noreste siempre hay que tener "un pie en cada lado" de la frontera (Galindo, 2003). Su situación geográfica ha marcado profundamente el desarrollo histórico y cultural de este amplio territorio desde la prehistoria, al constituirse como una zona de paso entre las amplias llanuras de Norteamérica y lo que fue Mesoamérica (Murray, 2012) (figura 1). Es por ello que algunos aspectos culturales se encuentran presentes desde las tierras del norte (Texas) hasta las tierras del golfo de México, al sur (Ramírez, 2011).

El poblamiento del noreste de México se remonta, como mínimo, a principios del Holoceno (Arcaico temprano) (ca. 10000 BP) (Valadez, 1999; Valadez y Carpinteyro, 2011). Los grupos del Noreste y, en general, de todo el Norte, fueron conocidos genéricamente como "chichimecas" por los pueblos mesoamericanos. Bernardino de Sahagún (Historia General... Lib. X, Cap. 29) decía de ellos que eran "gentes bárbaras que se sustentan de la 
caza que toman y no pueblan". Según las crónicas, “cada familia o rancho, o dos juntos, andan por los montes, viviendo dos días aquí y cuatro acullá" (De León, 1909: 34). Que hasta la fecha no se conozcan asentamientos prehispánicos permanentes en la región corrobora estas descripciones.

Los pueblos del Noreste se movían por el territorio en campamentos temporales, a cielo abierto o utilizando cuevas y abrigos rocosos, a los que volvían con regularidad. Estaban organizados en pequeñas bandas nómadas de filiación familiar, aparentemente sin una organización sociopolítica compleja, y con una estrategia de subsistencia de bajo impacto ecológico basada en la caza, la pesca y la recolección. Eran grandes cazadores y pescadores que utilizaban el atlatl (propulsor lanzadardos), hondas y arcos y flechas. Los arcos se realizaban generalmente de raíz de mezquite y las flechas de carrizo endurecido, con puntas de pedernal con pedúnculo y muescas laterales que se sujetaban a la caña con sautle (betún) o tendones de animales, principalmente de venado. Usaban, asimismo, cuchillos de pedernal con una hoja que se unía con sautle a un mango de madera. Se cazaba prácticamente cualquier animal (aves, conejos, víboras, insectos, etc.), con predilección por los venados. Por lo general, la carne era asada en fogones o barbacoas, y se repartía entre los miembros del grupo. Igualmente, se consumía sal, raíces y todo tipo de frutos, así como las hojas, el corazón y las flores de los cactus. Las tunas, por ejemplo, se consumían crudas, secas o en forma de licor, y con las vainas del mezquite se hacía una harina con la que se elaboraba el mezquitamal, que se consumía de diferentes maneras durante meses. Los alimentos vegetales se molían en piedras de molienda y morteros de madera o esculpidos en las rocas, y a menudo se cocían en fogones y hornos subterráneos (De León, 1909; Powell, 1977; Santa María, 1973).

Los documentos históricos fueron bastante prolíficos en la descripción de este tipo de actividades cotidianas, sobre todo en lo referente a la tecnología y la guerra por un interés eminentemente militar. También describen algunas de sus prácticas sociales y rituales, aunque solo fuera para demostrar el grado de "barbarie", la presencia del demonio o para justificar la presencia hispana, pues "entre estas gentes de este Reino, como más torpes de entendimiento, más crueles y bestiales, no necesitó el demonio de buscar artes ni nuevas maneras para engañarlos" (De León, 1909: 47). De este modo, a través de los textos es posible vislumbrar de forma indirecta el mundo simbólico de estos grupos y cómo percibían e integraban el entorno natural en sus actividades.
Como otros pueblos cazadores y recolectores nómadas, los pueblos del Noreste mantuvieron un profundo vínculo con la naturaleza y sus diversas manifestaciones, con los animales y plantas, el agua, las cuevas y las montañas, las estrellas, el Sol y la Luna, etc., con los que construyeron una percepción particular de la realidad que se materializaba en la manera en que organizaban y estructuraban el paisaje y el modo en que con él se relacionaban.

La movilidad era una estrategia de supervivencia, definida y regida por un calendario ritual basado en los ciclos naturales, destinado tanto a obtener los recursos como para llevar a cabo la reproducción de sus prácticas sociales. Por un lado, el ciclo de la recolección de alimentos, vegetales y animales establecía la relación entre las estaciones del año y los recursos. Al mismo tiempo, este ciclo se relacionaba espacialmente con lugares específicos en donde se realizaban determinadas prácticas.

En definitiva, los recorridos estacionales convertían el territorio en una especie de escenario espacio-temporal, en un paisaje estructurado que recorrían durante un ciclo anual de actividades predeterminado (figura 2).

El panorama, de este modo, era mucho más complejo y elaborado de lo que las fuentes escritas relataban. Los españoles, por cultura e interés, describían las sociedades indígenas como "bárbaras", simples y de corte igualitario, al realizar sus actividades de forma colectiva. No obstante, es probable que algunas de ellas estuvieran supervisadas, sino controladas, por un especialista ritual, el chamán, un agente mediador entre el mundo físico y espiritual, entre los miembros de la comunidad y lo sobrenatural.

En el Noreste, las prácticas funerarias, las reuniones (o mitotes) y los lugares con arte rupestre han sido comúnmente asociados a fenómenos y actuaciones de tipo chamánico (Turpin, 1990; Valadez, 1997). El chamán intervenía en diversos aspectos de la vida social, en los ritos de paso, la predicción de la caza y la guerra, la transmisión del conocimiento ancestral, la sanación o durante los mitotes, que eran "la cosa más común y que frecuentan mucho los indios en esta tierra (...); los cuales sirven en todas ocasiones" (De León, 1909: 43). En los mitotes, los miembros de un grupo se reunían entre sí o con grupos vecinos, y se realizaban con fines diversos y en diferentes momentos del año, ya fuese para la recolección de ciertas plantas, la caza, la celebración de fenómenos astronómicos o realizar intercambios de bienes materiales y/o simbólicos (Valadez, 1997). Algunos escritos describen que sobre todo servían para establecer lazos 

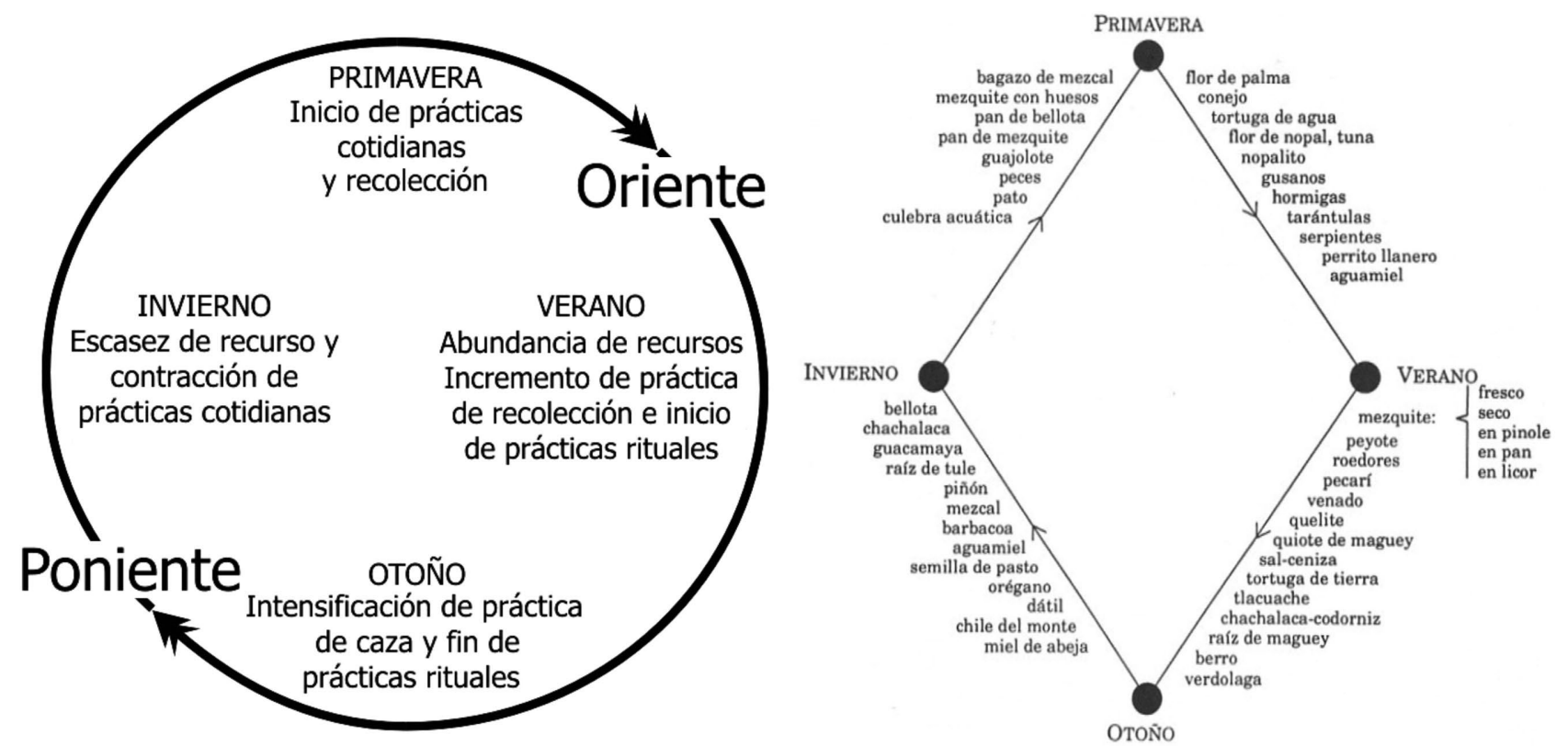

Figura 2. Calendario de prácticas sociales (izq.) (modificado de Corona, 2004: 71). Ciclo estacional alimentario (der.) (Valdés, 1995: 71).

sociales, alianzas y, especialmente, para declarar la guerra (De León, 1909; Santa María, 1973), algo habitual tras la llegada de los europeos.

Desde el primer momento, la ocupación de las tierras y las constantes incursiones, conocidas como "mariscadas", para capturar y esclavizar a los indígenas (Osante, 1997), convirtieron el Noreste en un espacio de confrontación permanente (Powell, 1977; Hoyo, 2005; Jiménez, 2006). La venta de esclavos indios para abastecer las minas y obrajes del sur fue un negocio lucrativo y el principal producto de exportación en Nuevo León hasta bien entrado el siglo XVII, provocando "la exasperación, el odio, la justa protesta y el deseo de venganza (...) entre aquellos nómadas así perseguidos y acosados" (Hoyo, 2005: 316) y la reproducción cíclica de la violencia.

La presencia novohispana se incrementó en el último cuarto del siglo XVIII con la implantación del sistema de misiones y presidios, lo que transformó definitivamente un modo de vida que se había mantenido, más o menos inalterado, desde la prehistoria. A finales de siglo XIX, los pueblos indígenas nómadas del Noreste habían sido prácticamente exterminados o asimilados.

\section{El arte rupestre en el Noreste}

En toda Norteamérica apenas hay sitios con evidencias de arte rupestre que hayan sido reconocidos para el periodo Paleoindio (desde el poblamiento del continente hasta el inicio del Holoceno, ca. $11000 \mathrm{BP}$ ). Esto no significa que no existan, sino que o bien no se han encontrado o no se han identificados como tales, sobre todo porque la mayoría de las dataciones han sido tradicionalmente cuestionadas por los defensores de la tesis Clovis (Whitley, 2013). No obstante, el ejemplo de Winnemucca Lake (Nevada, Estados Unidos), con dataciones entre 14800 y 10500 BP, en paralelo con la ocupación humana de la región, atestigua la presencia de arte rupestre desde los primeros momentos del poblamiento (Benson et al., 2013; Whitley, 2013) y sustenta la hipótesis que probablemente sucediera lo mismo en otras partes de Norteamérica a medida que fue poblándose. Ciertamente, no sería razonable pensar que los mismos grupos que dejaron constancia de su creatividad artística y pensamiento simbólico en artefactos de piedra y hueso de gran antigüedad (13000-9000 BP) (Lemke et al., 2015), no hubieran hecho lo mismo que hicieron sus antepasados en el Viejo Mundo y que, posteriormente, también harían sus descendientes en otros lugares del continente.

El arte rupestre es abundante, por ejemplo, en el norte de México, que concentra más de la mitad de los sitios del país (Viramontes et al., 2010). En el Noreste, la particular orografía de serranías, cañones y desfiladeros de la Sierra Madre Oriental favorece la presencia de cuevas y abrigos rocosos, utilizados como soporte para el arte rupestre 
desde al menos el Arcaico temprano (ca. 10000 BP) (Valadez y Carpinteyro, 2011) hasta el siglo XIX. Coahuila y Nuevo León albergan buena parte de ellos, sólo superadas en número por Baja California (Murray, 2007). Por su parte, en Tamaulipas su presencia, aun siendo importante, sobre todo de representaciones pictóricas, es menos conocida (Ramírez, 2015). Esta amplia distribución por prácticamente todo el territorio permite realizar análisis tanto a escala local como regional.

Algunos de los motivos representados parecen ser propios de una determinada zona, mientras que otros están presentes en distintos lugares. Que motivos semejantes se encuentren en sitios alejados entre sí, incluso en diferentes lugares del mundo, se ha tratado de explicar, no sin serias críticas (Helvenston et al., 2003; Bahn, 2010), por la existencia de patrones universales de tipo neurofisiológico, que harían que los estados alterados de la conciencia causados por las actividades chamánicas generaran las mismas imágenes en todos los individuos con independencia del tiempo y del espacio (Clottes y Lewis-Williams, 1996; Lewis-Williams, 2002).

No obstante, en la traslación de esas imágenes de la mente a su representación física debió de mediar una interpretación individual, momento en el que incidiría, de forma transcendente, el contexto personal y colectivo del creador, es decir, sus propias experiencias y conocimientos, los de su grupo y los de aquellos que debían de observar lo representado. Podría existir, entonces, una manifestación psicovisual de origen fisiológico que sería compartida como especie, y otra basada en un código compartido de carácter cultural, más restringido geográficamente. Al existir una localidad relacionada con quienes generaron el arte rupestre, su decodificación también requiere conocer el sistema asociativo y simbólico utilizado localmente, lo que permitiría aproximarse al funcionamiento interno de estos grupos.

Aunque las temáticas, técnicas, estilos, frecuencias, etc. pueden variar de un periodo a otro o de un sitio a otro, todo ello es una fuente de información esencial sobre sus creadores. Describe las actividades económicas y sociales, las ideas, creencias y prácticas, y proporciona una perspectiva única que puede ayudar a definir patrones culturales específicos. La representación de artefactos, por ejemplo, revela la tecnología; la ilustración del sistema de creencias informa sobre la relación con la naturaleza y cómo se percibía; y los motivos de animales o plantas, entre otros aspectos, nos aproximan al ecosistema existente en el momento de su creación, e informa sobre los cambios que se han producido en este a lo largo del tiempo.
Es importante destacar, asimismo, que el arte rupestre se crea en un soporte físico que se encuentra en un espacio determinado y definido socialmente. Cada práctica tiene su propio espacio, que no es escogido al azar sino que responde a una intencionalidad consciente con la que se pretende su apropiación, transformación y reconstrucción, de tal modo que se convierte en paisaje (Bradley, 1991). Por tanto, el paisaje es un concepto dual, bidimensional, que aúna lo físico con lo mental, lo material con lo simbólico (Thomas, 2012), que se crea con la práctica y el imaginario, y se constituye como un sistema de referencia espacial en donde las acciones humanas interrelacionan, de manera que resulten inteligibles (Gosden y Head, 1994).

Al ser un bucle de creación, cambio y transformación históricamente constituido, es posible analizar este proceso a lo largo del tiempo. El estudio de las materializaciones de las actividades en el territorio, como los sitios con arte rupestre, su jerarquización y organización espacial, permite conocer el paisaje creado, sus relaciones, articulaciones y, en definitiva, su patrón de racionalidad (Criado, 1999). De este modo, en la interpretación del arte rupestre es necesario incluir no solo el contexto natural sino también la construcción cultural del paisaje, pues al contextualizarlo se incorporan elementos tangibles e intangibles que permiten una aproximación más precisa al mundo de quienes lo crearon, en este caso, cazadores recolectores, y a los mensajes que dejaron en la roca. Sin esta integración, con dificultad se entiende esta información.

El arte rupestre en el Noreste se materializó en las cuevas y abrigos, pero también en rocas y objetos portátiles. En estos soportes, a través de un lenguaje visual se creó un sistema polisémico de representaciones con el que registraron su pensamiento simbólico y sus creencias, la percepción que tenían del mundo real y espiritual, y cómo percibieron y utilizaron el territorio en su cotidianidad, con el que establecieron una relación de tipo sistémico. De esta manera, los pueblos del Noreste se apropiaron del entorno natural y lo transformaron en paisaje, lo que incluye la forma de concebir la naturaleza, el espacio, el tiempo y las relaciones sistémicas e interactivas entre sujetos, y entre éstos y su entorno.

Los cazadores recolectores nómadas registraron en la roca todo aquello que consideraron relevante para reproducir y perpetuar su modo de vida, dotando de significado a unos lugares y no a otros. Con ello establecieron una jerarquía que organizaba el entorno a partir de la creación de espacios significativos, que son elementos 
activos en el proceso de configuración del espacio social. De este modo, la disposición espacial de los sitios con arte rupestre y los motivos representados tenían una lógica que estaba determinada, como ya se ha apuntado, por el movimiento de la población en el territorio y las actividades que cíclicamente se realizaban en cada uno de esos espacios, lo que se evidencia en la ocupación de unos lugares y no de otros en momentos y periodos también muy concretos. El arte rupestre del Noreste se convirtió, de esta manera, en portador de valores identitarios al mismo tiempo que de territorialidad, y se erigió en el soporte en donde se materializaron realidades particulares, cumpliendo una función esencial en la reproducción social de las prácticas simbólicas que se realizaban en contextos muy definidos.

Un buen número de los sitios arqueológicos documentados se han encontrado cerca de lugares con arte rupestre, de manera que cada uno de estos espacios probablemente estuvo ligado a la realización de ciertas actividades cotidianas, como la caza, el acceso al agua o el procesamiento de los recursos, o a otras más excepcionales, como sus prácticas sociales, religiosas y rituales. Entre estas prácticas se encuentran las funerarias, que en el Noreste se realizaron bajo diferentes patrones (Valadez, 2001; González, 2006). Uno de ellos es el enterramiento en zonas con arte rupestre, como en Cueva Ahumada y Boca de Potrerillos (Nuevo León), en asociación directa e indirecta con petrograbados o pinturas rupestres. En estos casos, se aprecia la voluntad de escoger espacios rituales o significativos para llevar a cabo los enterramientos, así como una clara intención de ocultar el lugar del mismo. Estos enterramientos suelen localizarse en las partes medias y elevadas de los cerros, en lugares con mayor concentración de motivos y bajo las paredes de los abrigos con pinturas rupestres (Valadez, 2001).

En general, en el Noreste son más numerosos los sitios con petrograbados que con pintura rupestre, aunque también se encuentran compartiendo no solo el mismo espacio sino, incluso, los motivos representados (Murray, 2007). En Chiquihuitillos y Cueva Ahumada (Nuevo León), por ejemplo, algunas pinturas están asociadas con petrograbados. En ambos casos, las pinturas pertenecen al llamado estilo "Chiquihuitillos", que se extiende por el oriente de Coahuila, centro y norte de Nuevo León, y noroeste de Tamaulipas. Este estilo se caracteriza por pinturas policromas, con preferencia por el rojo, aunque también se utilizan tonos de naranja y amarillo, y bicromía de gran contraste entre el negro y el blanco, diseños geométricos angulares, y a veces con superposiciones (Turpin et al., 2007; Valadez, 2017). Asimismo, en 2006 se descubrieron en la Sierra de San Carlos (Tamaulipas), casi 5000 pinturas en un excelente estado de conservación, con gran variedad de temas y estilos (García Sánchez, 2012; Ramírez, 2015).

También se han hallado en varios sitios de Nuevo León y Coahuila, e incluso Texas, pequeñas placas líticas y rocas móviles con incisiones y pinturas, con una iconografía similar a los motivos abstractos de los petrograbados y pinturas de la misma región (figura 3). Su presencia en este arte mobiliar sugiere que ambos medios formaban parte del mismo sistema simbólico (Turpin et al., 1996; Eling, 2002; Turpin y Eling, 2003). Algunos de estos objetos se encontraron en Cueva Ahumada (Nuevo León) asociados a fogones, pigmentos, conchas, plantas (algunas alucinógenas), huesos de animales y artefactos líticos, quizás siendo parte de un mismo ritual o actividad (Corona, 2001).

En el arte rupestre suelen dividirse los motivos en "representativos" o "figurativos" y en "abstractos", aunque es posible que esta distinción se deba, sobre todo, a la capacidad para poder asociar los motivos con realidades conocidas. En el Noreste, unos motivos se asocian con relativa facilidad con animales, plantas, figuras antropomorfas, artefactos, etc., mientras que otros tienen un significado mucho más complejo de identificar, lo que hace necesario enfatizar el contexto para su interpretación.

En el primer grupo se encuentran los motivos antropomorfos, que representan posibles personajes míticos y/o chamanes. A pesar de ser relativamente escasos en época prehispánica, suelen encontrarse sobre todo en espacios considerados de carácter privado, en donde el chamán dirigiría la actividad que allí se realizara (Corona, 2004).

Por el contrario, los motivos que evidencian el carácter cazador recolector de las poblaciones del Noreste son abundantes y relativamente fáciles de identificar. Se corresponden, por ejemplo, con motivos que reproducen vegetales como el peyote y presas como el venado de cola blanca, el borrego cimarrón, el bisonte, etc., así como sus elementos distintivos (cuernos, cornamentas, huellas, etc.) (figura 4).

También se encuentran imágenes de los artefactos del cazador, como el atlatl, puntas de proyectil de diversos tipos, raspadores, cuchillos enmangados, etc. (figura 5), a veces en solitario o asociados a las imágenes anteriores. Este tipo de grabados suelen ubicarse en espacios 

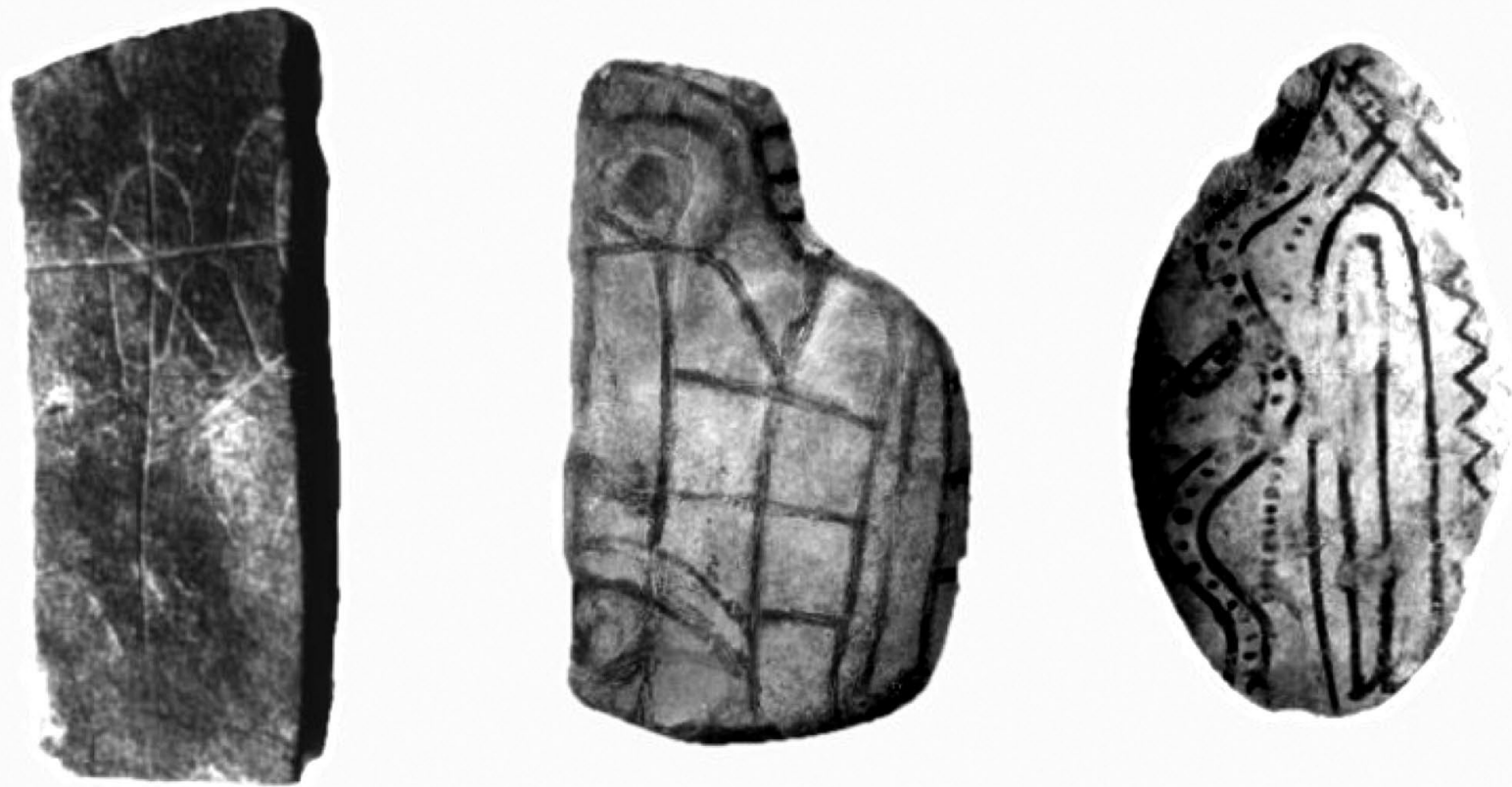

Figura 3. Arte mobiliar del Noreste (Corona, 2004: 19).

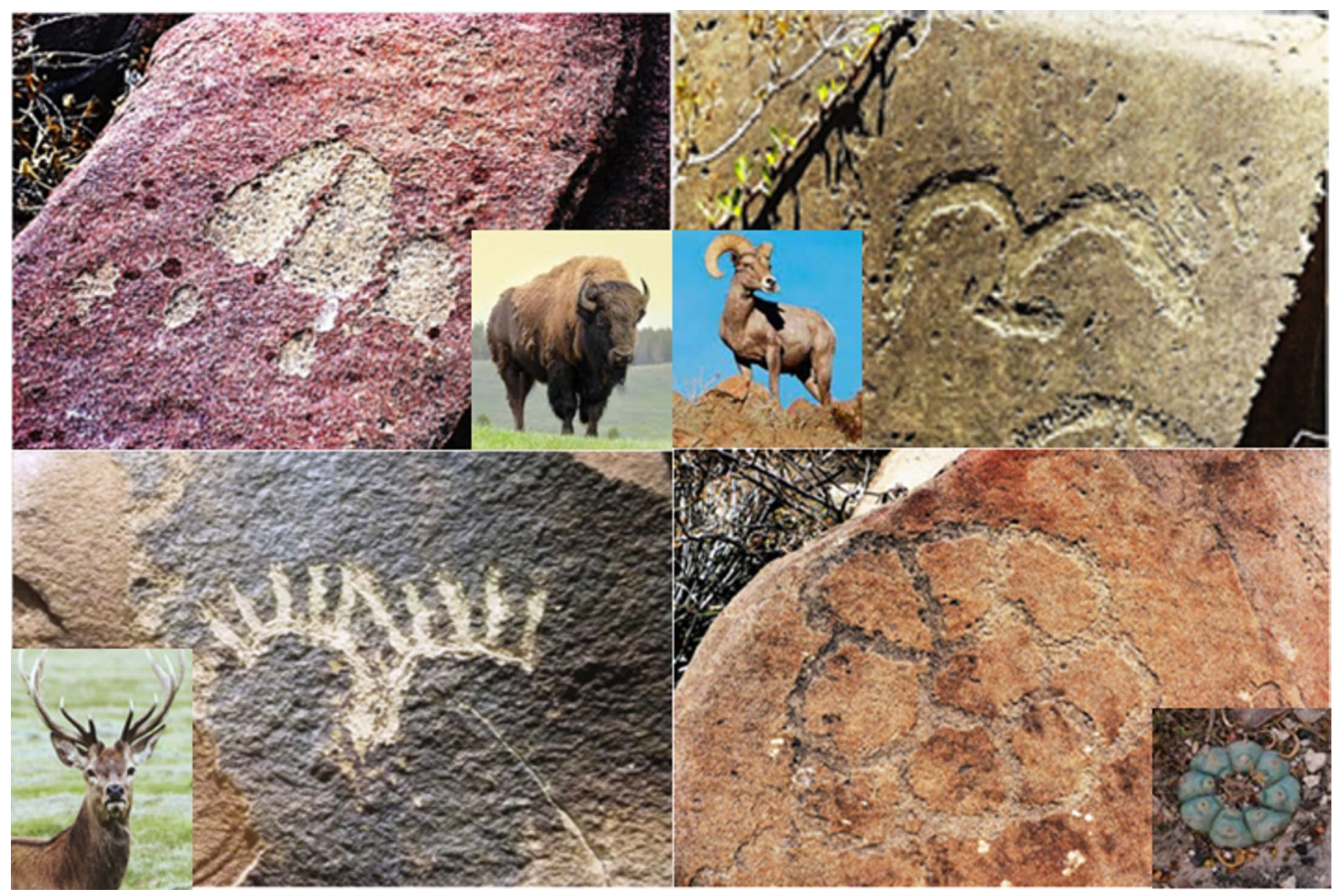

Figura 4. Motivos animales y vegetales. 
cercanos a los lugares propicios para la caza, como fuentes de agua o desfiladeros. En las bocas de los cañones, por ejemplo, estos motivos son recurrentes.

Algunas pruebas experimentales han relacionado el alcance medio del atlatl, de unos 40-50 metros, con la distancia existente entre los motivos y el sitio de caza. En esta relación, generalmente los grabados están situados en alto y por encima del lugar de caza, de manera que el tiro se realizaría desde una situación de ventaja y sería más fácil de ejecutar (Murray y Lazcano, 2001).

Este tipo de manifestaciones, por separado o relacionadas, probablemente tuvieron una connotación propiciatoria asociada con la magia o creencias simpáticas, especialmente si se encuentran asociadas con campamentos temporales de caza, lo que ayudaría a comprender el contexto (Turpin, 1992).

Aunque se ha considerado una hipótesis excesivamente simplista (Clottes y Lewis-Williams, 2007), desde este punto de vista formarían parte de una invocación para obtener un buen resultado en la caza o celebrar su éxito, como acto de expiación por la muerte

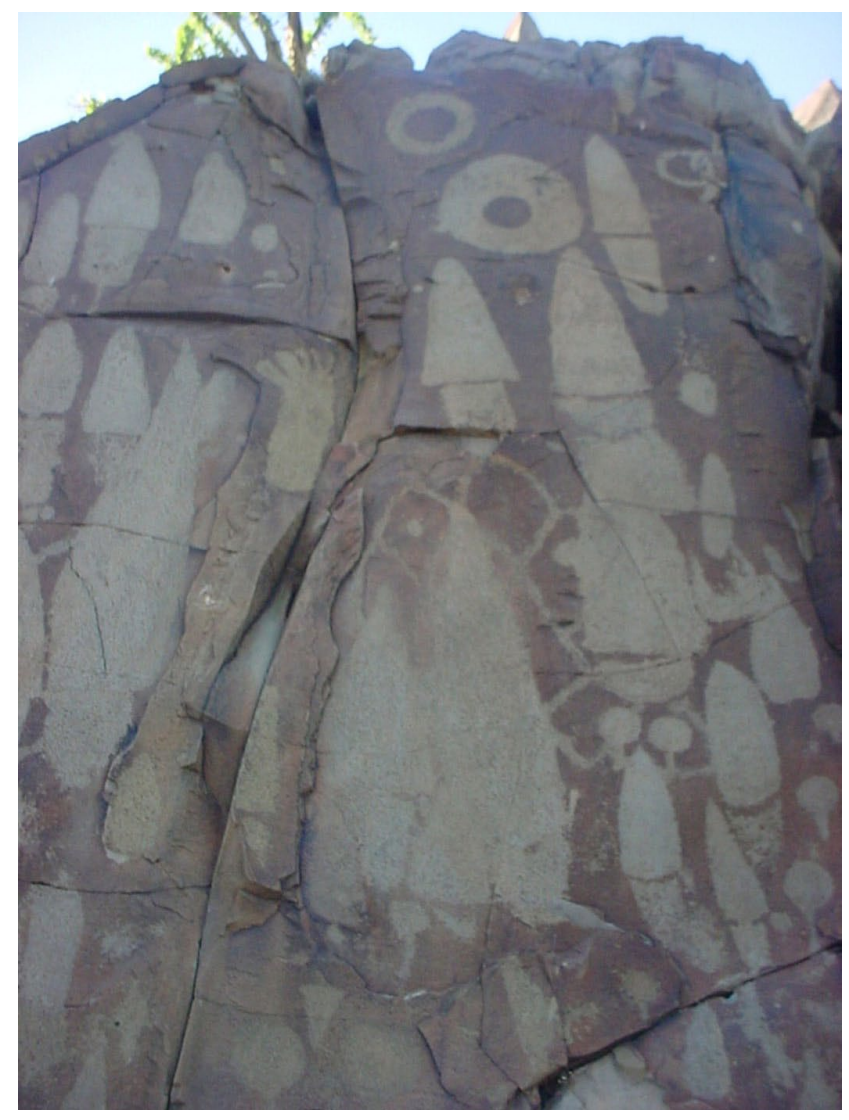

Figura 5. Panel de cuchillos enmangados. Cerro Bola (Coahuila). Foto: C. Corona. del animal o exhorto para su fecundidad, o para que el cazador adquiriera las habilidades de determinado animal (Turpin, 1992).

Es de destacar cómo la tecnología se refleja en el arte rupestre. Durante miles de años, el atlatl fue el arma principal de caza en el Noreste, mientras que el uso del arco se generalizó en Texas entre el 700-1000 d.C. (Turner et al., 2011), desde donde se difundió hacia el sur. Esto tiene importantes consecuencias, porque su aparición en las representaciones rupestres puede utilizarse de marcador para datarlas de forma relativa.

Por otro lado, tanto en la pintura rupestre como en los petrograbados se tiende, de forma general, hacia las representaciones esquemáticas de motivos geométricos (Corona, 2004). Líneas rectas, onduladas y curvas, que se cortan, interconectan o interceptan otros elementos, círculos, conjuntos de puntos, etc., entrarían en la categoría de los motivos "abstractos", y pudieron manifestar en la roca elementos o aspectos de la naturaleza de forma esquemática y simbólica.

Algunas de las imágenes parecen referirse al culto o invocación al agua, a la lluvia y a sus fenómenos asociados, utilizando líneas rectas, paralelas, sinuosas, verticales, en zigzag, círculos concéntricos, etc. Por ejemplo, los llamados "ojos" o "nubes" de lluvia en Chiquihuitillos (Nuevo León) (figura 6) parecen simbolizar la lluvia que cae desde una nube estilizada, cuyas líneas zigzagueantes verticales representarían los rayos y relámpagos (Turpin et al., 2007). Según el testimonio de uno de los últimos indígenas de la región, estas formas foliáceas horizontales eran "ojos que lloran desde el cielo" u "ojos de las nubes"; las líneas verticales que parten del centro de esas figuras eran la lluvia; las líneas quebradas en zigzag eran los truenos y rayos (relámpagos), que representaban "el

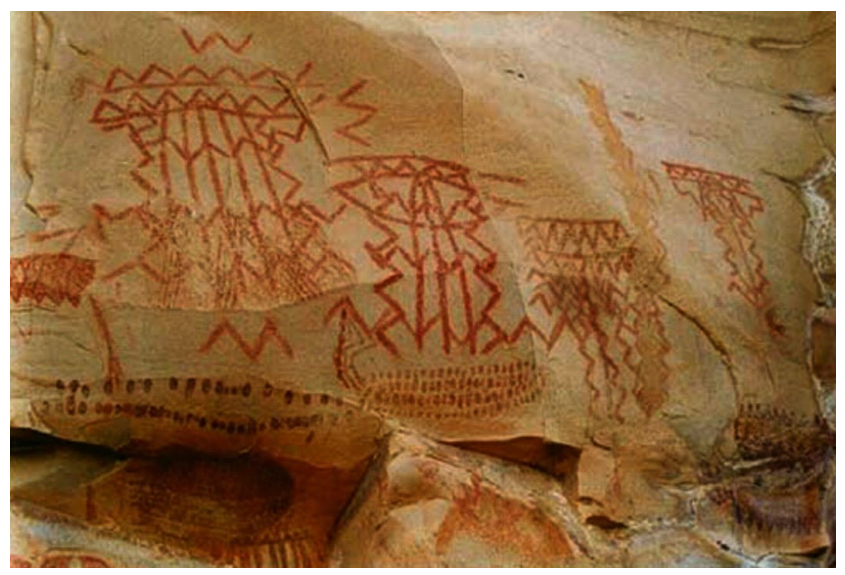

Figura 6. Chiquihuitillos (Nuevo León). Foto: C. Corona. 


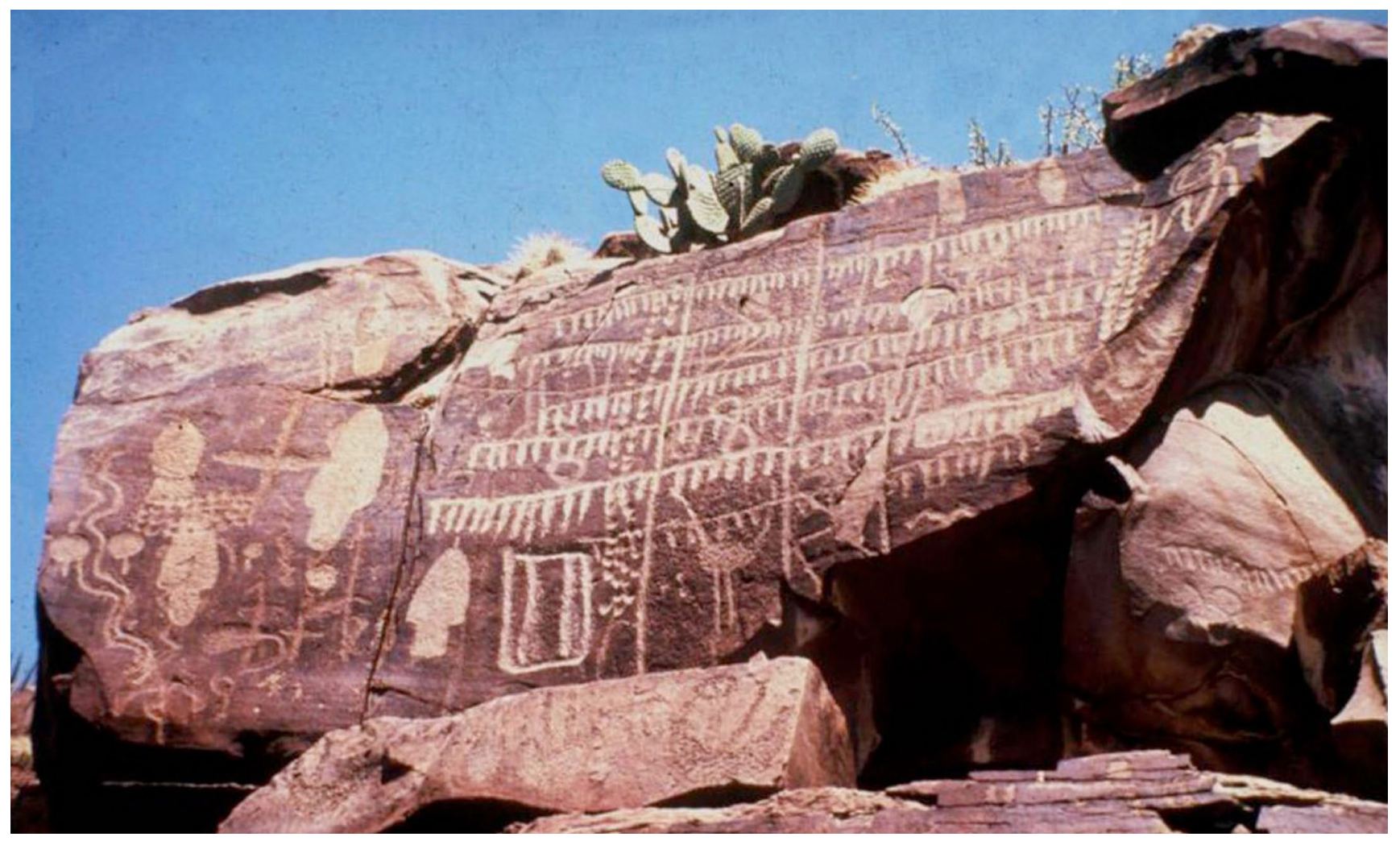

Figura 7. Panel. Presa la Mula (Nuevo León). Foto: C. Corona.

llanto y lamento de las nubes"; los puntos que se observan en la parte inferior eran "las gotas que pintan la tierra”, es decir, las primeras gotas de lluvia; y las líneas onduladas que parten de las series de puntos eran "los arroyos que se llevan el agua de lluvia por los valles" (Valadez, 2017: 65).

La mayoría de este tipo de imágenes suelen localizarse en lugares próximos a arroyos o fuentes de agua, y a veces también se encuentran asociadas a motivos de animales y artefactos, probablemente por ser lugares especialmente propicios para la caza.

Los indígenas del Noreste tenían, asimismo, importantes conocimientos de carácter astronómico de los que dejaron constancia en el arte rupestre (Murray, 2015). Algunas de estas imágenes podrían representar o registrar direcciones cardinales, el sol, la luna, las estrellas, cometas, estrellas fugaces, etc. Estas representaciones solían ubicarse en zonas abiertas y con amplia visibilidad, lo que permitiría no solo observar el cielo sino también servir como puntos de observación desde donde tomar como referencia determinados rasgos del paisaje que serían utilizados como marcadores para registrar eventos estacionales, como los solsticios y equinoccios
(Corona, 2005). Otras imágenes parecen referir un culto a rasgos geográficos del paisaje, representando el perfil de un horizonte o de un determinado cerro, o señalando geoformas del paisaje que tendrían connotaciones especialmente significativas para el observador (Valadez, 2017).

Un conjunto particular de motivos rupestres son las llamadas cuentas o puntos (figura 7), que podrían estar relacionados con el cálculo o registro de determinados fenómenos naturales, como los periodos lunares u otros eventos celestes y estacionales. Se ha sugerido, asimismo, que podrían representar una cuenta de los periodos de gestación de ciertos animales, que en esas ocasiones también figurarían en el panel (Murray, 2012). E incluso que serían un posible antecedente del sistema binomial (puntos y rayas) de conteo mesoamericano (Murray, 1996).

\section{El arte rupestre durante el periodo colonial en el Noreste}

Como sucede con otros aspectos de las culturas del Noreste, las fuentes escritas prácticamente no mencionan 

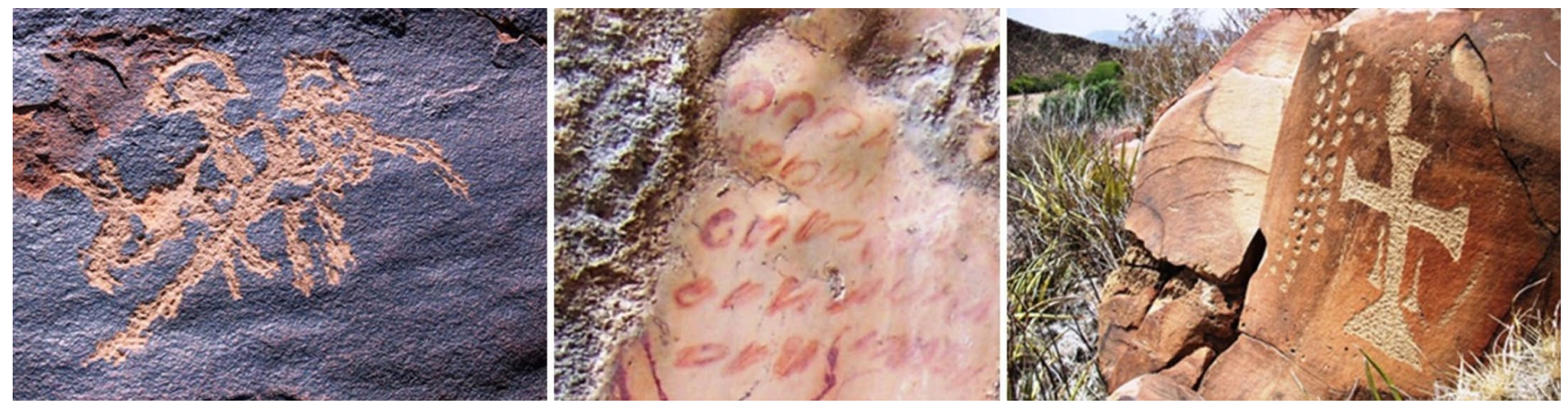

Figura 8. Representaciones rupestres históricas (Encinas, 2014).

las manifestaciones rupestres, a pesar que siguieron realizándose durante la Colonia y en época republicana. Su estudio arqueológico, por tanto, como ya se ha mencionado, es fundamental para su conocimiento. El arte rupestre en el Noreste es un claro ejemplo de la pervivencia, con todos los matices, de una tradición cultural a lo largo del tiempo, cuya comprensión, por tanto, también debe de situar la información en un amplio contexto temporal. En ocasiones, la arqueología así lo ha intentado, al aproximarse al periodo colonial situándolo en el marco de una cadena histórica mucho más dilatada, relacionando la prehistoria con la arqueología histórica (Lightfoot, 1995) de manera que entre una y otra se pudiera contextualizar más adecuadamente los datos. Bajo esta premisa, el arte rupestre prehistórico, protohistórico y colonial formaría un continuum cuyo estudio integrado permitiría observar el proceso de conquista y colonización del Noreste, sus tiempos y consecuencias, formando parte de una cadena de acontecimientos. La llegada de los europeos supuso un cambio tan trascendente en la vida de los pueblos nativos que este contacto, la mayor parte de las veces dramático, fue plasmado en paredes y rocas. Y no solamente por ellos.

En un nuevo contexto histórico, en el Noreste y, en general, en toda Norteamérica, se produjo un cambio en las temáticas representadas, y el lenguaje visual del arte rupestre pasó de ser una comunicación simbólica a otra prácticamente literal (Turpin, 2002). En las pinturas y grabados rupestres indígenas comenzaron a ser comunes las representaciones de los recién llegados y de lo que llevaban consigo, así como las escenas de violencia que acompañaron a este proceso, como si se quisiera, de esta manera, reivindicar el territorio al mismo tiempo que dejar constancia de lo que estaba sucediendo (Turpin, 1988, 1989; Turpin y Eling, 2007).

Para este periodo son abundantes las representaciones de religiosos, soldados y animales domésticos, así como de escopetas, puntas de flecha de metal, espadas, cuchillos, hachas, etc., que aparecen asociados tanto a europeos como utilizados por los indígenas en escenas de combate y caza. Esto permite no solamente datar estas representaciones sino también identificar los contextos con los que están asociadas (Keyser y Kaiser, 2010). Incluso se ha establecido una cronología temática a partir de los diferentes motivos representados, que refiere un primer momento de curiosidad (representación de europeos, animales y armas); más tarde de conflicto (escenas de combate y grafitis); y finalmente de imposición de la nueva fe (motivos religiosos) (Turpin y Eling, 2016).

La situación de guerra constante, así como la presión de los colonizadores sobre las poblaciones indígenas, provocaron su progresiva desintegración social, lo que eliminó "la unidad organizacional indispensable para la definición de estilos específicos de arte rupestre" (Turpin y Eling, 2007: 225). Con ello, el arte rupestre pasó de ser una expresión social de la tradición cultural a un acto meramente individual, y los espacios con arte rupestre, que hasta entonces habían sido un axis mundi para las sociedades indígenas, un lugar de comunicación entre lo material y lo inmaterial, perdieron su sentido original y el uso social que anteriormente habían tenido (Turpin y Eling, 2007).

Simultáneamente, en los mismos espacios y a través del mismo medio que los indígenas habían usado durante miles de años, los europeos dejaron su impronta de dominación (figura 8). Por un lado, destruyendo físicamente muchos de estos espacios o "cristianizando" otros a través de la superposición de motivos cristianos sobre los prehispánicos. Calvarios, iglesias y especialmente cruces se utilizaron a modo de exorcismo con el fin de expulsar al demonio de aquellos lugares e incorporarlos, 
una vez purificados, al nuevo orden.

Por otro lado, los europeos utilizaron la palabra escrita, el grafiti, con breves mensajes, tanto religiosos como civiles y militares, con los que relataban las escenas de conflicto y dejaban sus impresiones sobre los indígenas, a menudo con palabras y frases ofensivas y de menosprecio. Salvajes, bárbaros y gandules, pero también guerreros feroces y capaces de sobrevivir en un medio que era su mejor aliado (Turpin y Eling, 2016).

En el marco de una guerra de exterminio, el arte rupestre se convirtió en una herramienta de propaganda utilizada por unos y otros para para registrar su presencia y superioridad en la batalla (Turpin, 2002). Con estos actos, cada una de las partes pretendía imponerse a la otra en el espacio. Por ello, muchos de estos sitios se encuentran cerca de las fuentes de agua y en lugares potencialmente de combate (Turpin y Eling, 2016). Pero, sobre todo, quisieron adueñarse del relato: los indígenas negándose a desaparecer sin dejar rastro, y los europeos queriendo dejar constancia del nuevo poder y la nueva fe, simbolizando en la roca su apropiación del territorio.

La importancia del arte rupestre para estos momentos radica en que si bien las investigaciones arqueológicas han aportado un gran volumen de información sobre cientos de sitios prehispánicos y sus pobladores, todavía son relativamente insuficientes para el periodo colonial, que tradicionalmente ha sido estudiado desde otras disciplinas como la historia. El estudio del arte rupestre puede ayudar al conocimiento del momento del contacto y el impacto que supuso la llegada de los europeos al territorio, pues refleja en qué forma y medida esta circunstancia histórica afectó a las poblaciones indígenas y la manera en que se materializó, al convertirse en una herramienta narrativa utilizada por unos y otros para transmitir su relato particular de lo que estaba sucediendo.

\section{Conclusiones}

Cada práctica social tiene y define su propio espacio en el paisaje. Un espacio que es reconocible tanto por los miembros de una comunidad como, seguramente, por los de otros grupos. Algunos de estos lugares debieron de tener un carácter público, en cuanto a que servirían para realizar las prácticas sociales de la colectividad y la interrelación entre los diferentes agentes sociales. Otros serían de carácter privado, en donde un especialista ritual o chamán ejercía el dominio simbólico y supervisaría la actividad. Unos y otros, constituían espacios precisos para la realización de las prácticas rituales sustantivas que servían para el mantenimiento social del grupo.

En los espacios con arte rupestre, los cazadores recolectores del Noreste pintaron y grabaron unos motivos que venían determinados por su tradición cultural. Con ellos, dieron forma en el territorio a un mapa organizado de su realidad, en donde su disposición reflejaba la concepción de un paisaje definido y de un modelo conceptual del "tiempo social" en el cual el sistema de medición se basaba en la relación del tiempo físico con el calendario de sus prácticas sociales.

De este modo, la distribución del arte rupestre estuvo determinada por la percepción que tenían los cazadores recolectores del mundo que les rodeaba y por una cosmovisión que se expresaba en cada uno de los motivos representados. Las manifestaciones rupestres fueron incorporadas a estos lugares para dotarlos del carácter simbólico necesario para que diera trascendencia a las prácticas sociales y rituales que en ellos se realizaban. Al mismo tiempo, esta ocupación física y simbólica del entorno permitía revestir a la sociedad de una proyección espacial, dado que en estos sitios se pretendía destacar el dominio que tenía el grupo sobre la naturaleza.

En el paisaje, cada imagen y cada roca, cada elemento y cada actividad de la vida cazadora recolectora, debía de interactuar de una manera simbólica con los elementos y fuerzas de la naturaleza, para que en su conjunto se pudiera conformar un paisaje dinámico y sagrado que, por medio de rituales y ceremonias, cíclicamente veía reforzar su culto.

Todo ello cambió, drásticamente, con la llegada de los europeos. Pero incluso en esa circunstancia adversa para los grupos indígenas del Noreste, el arte rupestre siguió vivo, esta vez explicando nuevas y diferentes historias. Y su estudio es la ventana a través de la cual podemos aproximarnos a este pasado.

\section{Referencias}

BAHN, P. 2010. Prehistoric Rock Art: Polemics and Progress. Cambridge University Press, Cambridge.

BENSON, L. V.; E. M. HATTORI; J. SOUTHON y B. ALECK, 2013. Dating North America's oldest petroglyphs, Winnemucca Lake subbasin, Nevada. Journal of Archaeological Science, 40(12): 4466-4476.

BRADLEY, R. 1991. Rock Art and the Perception of Landscape. Cambridge Archaeological Journal, 1(1): 77-101.

CLOTTES, J. y D. LEWIS-WILLIAMS, 1996. Les chamanes de 
la Préhistoire. Transe et magie dans les grottes ornées. Le Seuil, París.

2007. Palaeolithic art and religion. En Penguin Handbook of Ancient Religions, J. R. Hinnells (Ed.), pp. 7-45. Penguin Books, London.

CORONA, C. 2001. Cueva Ahumada, un sitio arcaico en la Sierra Madre Oriental. Tesis de Licenciatura, ENAH-INAH, México.

2004. Paisajes arqueológicos del noreste de México: Estructuración de las prácticas sociales de los cazadores recolectores de Nuevo León y Coahuila. Tesis de Maestría. ENAH-INAH, México.

2005. Los Eventos Astronómicos en la Construcción del Espacio y el Tiempo en Cueva Ahumada, Nuevo León. En Perspectivas de la Investigación Arqueológica, W. Wieshau y P. Fournier (Eds), pp 109-122. INAH/ENAH, México.

CRIADO, F. 1996. La Arqueología del Paisaje como programa de gestión integral del Patrimonio Arqueológico. PH, Boletín Andaluz del Patrimonio Histórico, 14: 15-19.

DE LEÓN, ALONSO, 1909 [1649]. Relación y discursos del descubrimiento, población y pacificación de este Nuevo Reino de León; temperamento y calidad de la tierra. En Historia de Nuevo de León, con noticias sobre Coahuila, Tamaulipas y Nuevo México, T. XXV, G. García (Ed.), pp. 9-188. Librería de la Vda. de C. Bouret, México.

ELING Jr., H. H. 2002. El arte mobiliar del noreste de México. Relaciones, 23(92): 49-73.

ENCINAS, L. 2014. Las manifestaciones gráfico-rupestres del encuentro de dos mundos en el norte de México. Rupestreweb, Consultado el 20 de Julio de 2019. http://www.rupestreweb.info/dosmundosgraficorupestres.html

GALINDO, M. J. 2003. Con Un Pie En Cada Lado: Ethnicities and the Archaeology of Spanish Colonial Ranching Communities. Along the Lower Río Grande Valley. PhD. Diss. The University of Texas at Austin. Consultado el 15 de Agosto de 2019. https://repositories.lib.utexas.edu/ handle/2152/589

GARCÍA SÁNCHEZ, M. 2012. La presencia del arte rupestre en Burgos, Tamaulipas. Tesis de licenciatura, Universidad Autónoma de Zacatecas, Zacatecas.

GONZÁLEZ, L. 2006. Las cuevas mortuorias de Coahuila. Arqueología Mexicana, 14(80): 61-65.

GOSDEN, O y L. HEAD, 1994. Landscape - A Usefully Ambiguous Concept. Archaeology in Oceania, 29: 113-116.

HELVENSTON, P., P. BAHN, J. BRADSHAW y C. CHIPPINDALE, 2003. Testing the "three stages of trance" model. Cambridge Archaeological Journal, 13(2): 213-224.

HOYO, E. DEL, 2005. Historia del Nuevo Reino de León (15771723). ITESM/Fondo Editorial Nuevo León, Monterrey.

JIMÉNEZ, A. 2006. El gran Norte de México. Una frontera imperial en la Nueva España (1540-1820). Ed. Tébar, Madrid.

KEYSER, J. D. y D. A. KAISER, 2010. Getting the Point: Metal Weapons in Plains Rock Art. Plains Anthropologist, 55(214): 111-132.
LEMKE, A. K.; D. C. WERNECKE y M. B. COLLINS, 2015. Early Art in North America: Clovis and Later Paleoindian Incised Artifacts from the Gault Site, Texas (41bl323). American Antiquity, 80(1): 113-133.

LIGHTFOOT, K. G. 1995. Culture Contact Studies: Redefining the Relationship between Prehistoric and Historical Archaeology. American Antiquity, 60(2): 199-217.

LEWIS-WILLIAMS, J. D. 2002. The Mind in the Cave. Consciousness and the Origins of Art. Thames and Hudson, London.

MURRAY, W. B. 1996. The Northeast Mexican Petroglyphic Counting Tradition: a Methodological Summary. En Astronomical Traditions in Past Cultures, V. Koleva y D. Kolev (Eds.), pp. 14-24. Institute of Astronomy, Bulgarian Academy of Sciences, Sofia.

-2007. Introducción. En Arte rupestre del noreste, W. B. Murray (Comp.), pp. XI-XXIX. Fondo Editorial de Nuevo León, Monterrey.

2012. Early rock art of the Americas as reflected in the Northeast Mexican corridor. En L'art pléistocène dans le monde. Actes du Congrès IFRAO, Tarascon-sur-Ariège, 2010, J. Clottes (Dir.), pp. 643-654. Nº spécial de Préhistoire, Art et Sociétés, Ariege, Bulletin de la Société Préhistorique Ariège Pyrénées, LXV-LXVI, 2010-2011, CD.

2015. Astronomy and Rock Art in Mexico. En Handbook of Archaeoastronomy and Ethnoastronomy, C. Ruggles (Ed.), pp. 659-667. Springer, New York.

MURRAY, W. B. y H. LAZCANO, 2001. Átlatl Hunters of the Sierra Madre Oriental (México). En American Indian Rock Art, Vol. 27, S. M. Freers y A. Woody (Eds.), pp. 261-267. American Rock Art Research Association, Tucson.

OSANTE, P. 1997. Orígenes del Nuevo Santander (1748-1772). IIH-UNAM, Universidad Autónoma de Tamaulipas, México.

POWELL, PH. W. 1977. La guerra chichimeca (1550-1600). FCE, México.

RAMÍREZ, J. G. 2011. Naturaleza y cultura entre los indígenas nómadas cazadores-recolectores del Noreste de México. UDEM, Monterrey

RAMÍREZ, G. A. 2015. El arte rupestre de Tamaulipas. Problemática y retos para su estudio, conservación y puesta en valor. En Arte rupestre de México para el mundo. Avances y nuevos enfoques de la investigación, conservación y difusión de la herencia rupestre mexicana, G. A. Ramírez, F. Mendiola, W. B. Murray y C. Viramontes (Coords.), pp. 113123. Gobierno del Estado de Tamaulipas, Ciudad Victoria.

SANTA MARÍA, VICENTE DE, 1973 [ca. 1787-1789]. Relación Histórica de la Colonia del Nuevo Santander. UNAM, Nueva Biblioteca Mexicana no 27, México.

SAHAGÚN, BERNARDINO DE, 1830 [1577]. Historia General de las cosas de la Nueva España. Vol. III. Imprenta del ciudadano Alejandro Valdés, calle de Santo Domingo y esquina de Tacuba, México.

THOMAS, J. 2012. Archaeologies of Place and Landscape. En Archaeologiecal Theory Today, I. Hodder (Ed.), pp.165187. Polity Press, Cambridge.

TURNER, E. S., T. R. HESTER y R. L. MCREYNOLDS. 2011. 
Stone Artifacts of Texas Indians. Taylor Trade Publishing, Lanham.

TURPIN, S. A. 1988. Arroyo de los Indios: A Historic Pictograph Site in Northern Coahuila. Plains Anthropologist, 33(120): 279-284.

1989. The Iconography of Contact: Spanish Influences in the Rock Art of the Middle Rio Grande. En Columbian Consequences. Vol. 1: Archaeological and Historical Perspectives on the Spanish Borderlands West, D. H. Thomas (Ed.), pp. 277-299. Smithsonian Institution, Washington, D.C.

1990. Rock Art and Hunter-Gatherer Archaeology: A Case Study from SW Texas and Northern México. Journal of Field Archaeology, 17(3): 263-281.

1992. Hunting camps and hunting magic: petroglyphs of the Eldorado divide, west Texas. North American archaeologist 13(4): 295-316.

2002. Rock Art as Propaganda: Spanish and Native Inscriptions In the Bolsón de Mapimí, Northern Mexico. En Rock Art and Cultural Processes, S. A. Turpin (Ed.), pp. 91-117. Rock Art Foundation Special publication 3, San Antonio.

TURPIN, S. A. y H. H. ELING Jr., 2003. More Mobiliary Art from Northern Mexico: The Pelillal Collection. Plains Anthropologist, 48(187): 255-261.

2007. El choque de dos culturas en el arte rupestre de Coahuila. En Memoria del Seminario de Arqueología del Norte de México, C. García y E. Villalpando (Eds.), pp. 222229. CNA, INAH / Centro INAH Sonora, Hermosillo. 2016. Curiosity Conflict and Contact Period Rock Art of the Northern Frontier, Mexico and Texas. En La vitalidad de las voces indígenas: arte rupestre del contacto y en sociedades coloniales, F. Berraljalbiz (Ed.), pp. 275-298. UNAM, México.

TURPIN, S. A., H. H. ELING Jr y M. VALADEZ, 1996. The Mobiliary Art of Boca de Potrerillos, Mina, Nuevo Leon, Mexico. Plains Anthropologist, 41(156): 105-116.

2007. Hacía la definición de un estilo: las pictografías de Chiquihuitillos en el noreste mexicano. En Arte Rupestre del Noreste, W. B. Murray (Comp.), pp. 127-145, Fondo Editorial de Nuevo León, Monterrey.

VALADEZ, M. 1997. Prácticas chamánicas y el mitote en Nuevo León. Revista de Humanidades, 3: 191-199 1999. La arqueología de Nuevo León y el noreste. Universidad Autónoma de Nuevo León, Monterrey. 2001. Expiración, luto y defunción. Evidencias sobre prácticas mortuorias de los antiguos norestenses. Revista de Humanidades, 10: 121-131. 2017. Tiempo profano / Tiempo ritual. El paisaje prehistórico de los antiguos habitantes de Nuevo León. Tesis Doctoral. ENAH-INAH, México.

VALADEZ, M. y D. CARPINTEYRO, 2011. Nuevos datos sobre el hombre temprano en Nuevo León: Cueva La Morita II. En IV Simposio internacional El hombre temprano en América, J. C. Jiménez, C. Serrano, A. González y F. J. Aguilar (Eds.), pp. 235-258. UNAM, INAH, México.

VALDÉS, C. M. 1995. La gente del mezquite: los nómadas del Noreste en la colonia. Ciesas, México.

VIRAMONTES, C., M. L. GUTIÉRREZ, F. MENDIOLA y W. B. MURRAY, 2010. Continuing Progress in Mexican Rock Art Research, 2005-2009. En Rock Art Studies: News of the World $I V$, P. Bahn, N. Franklin y M. Strecker (Eds.), pp. 264-287. Oxbow Books, Oxford.

WHITLEY, D. S., 2013. Rock Art Dating and the Peopling of the 